\title{
A Simple Model of Optimal Deterrence and Incapacitation
}

\section{Citation}

Steven Shavell, A Simple Model of Optimal Deterrence and Incapacitation, 42 Int'l Rev. L. \& Econ. 13 (2015).

\section{Published Version}

http://dx.doi.org/10.1016/j.irle.2014.11.005

\section{Permanent link}

http://nrs.harvard.edu/urn-3:HUL.InstRepos:17367410

\section{Terms of Use}

This article was downloaded from Harvard University's DASH repository, and is made available under the terms and conditions applicable to Other Posted Material, as set forth at http:// nrs.harvard.edu/urn-3:HUL.InstRepos:dash.current.terms-of-use\#LAA

\section{Share Your Story}

The Harvard community has made this article openly available.

Please share how this access benefits you. Submit a story.

Accessibility 


\title{
HARVARD
}

JOHN M. OLIN CENTER FOR LAW, ECONOMICS, AND BUSINESS

\section{A SIMPLE MODEL OF OPTIMAL DETERRENCE AND INCAPACITATION}

\author{
Steven Shavell
}

Forthcoming in International Review of Law and Economics

Discussion Paper No. 802

$12 / 2014$

Harvard Law School

Cambridge, MA 02138

This paper can be downloaded without charge from:

The Harvard John M. Olin Discussion Paper Series: http://www.law.harvard.edu/programs/olin_center/

The Social Science Research Network Electronic Paper Collection:

http://ssrn.com/Abstract $=2534579$ 


\title{
A Simple Model of Optimal Deterrence and Incapacitation
}

\author{
Steven Shavell
}

The deterrence of crime and its reduction through incapacitation are studied in a simple multiperiod model of crime and law enforcement. Optimal imprisonment sanctions and the optimal probability of sanctions are determined. A point of emphasis is that the incapacitation of individuals is often socially desirable even when they are potentially deterrable. The reason is that successful deterrence may require a relatively high probability of sanctions and thus a relatively high enforcement expense. In contrast, incapacitation may yield benefits no matter how low the probability of sanctions is-implying that incapacitation may be superior to deterrence.

Keywords: crime, deterrence, incapacitation

JEL codes: K14, K42

1. Introduction

The deterrence of crime - its discouragement by means of the threat of imprisonmentand the reduction of crime through incapacitation - its direct prevention as a result of actual imprisonment — are two primary purposes of imprisonment. In order to study incapacitation along with deterrence, I examine a setting in which individuals make decisions over time whether to commit crimes. Under that assumption, a person who is not deterred from committing a crime and is caught and imprisoned would be prevented from committing other crimes when he is in prison. This outcome could yield an incapacitation benefit, for the person might have decided to commit further crimes had he not been in prison. ${ }^{1}$

In particular, I consider in Section 2 a simple model involving decision making over time about crime, namely, a model in which individuals live two periods and make decisions each period whether to commit crimes (which are presumed to be socially undesirable acts) in the face

\footnotetext{
* Samuel R. Rosenthal Professor of Law and Economics, Harvard Law School. I thank Nuno Garoupa, Louis Kaplow, and A. Mitchell Polinsky for comments, Julian Joiris for research assistance, and the John M. Olin Center for Law, Economics, and Business at Harvard Law School for research support.

${ }^{1}$ Such an incapacitation benefit is latent in any multiperiod model of deterrence of crime through the use of imprisonment.
} 
of the threat of imprisonment sanctions. Individuals might be potentially deterrable-possible to deter employing a feasible sanction and a probability of its imposition-or undeterrableimpossible to deter.

I initially determine the optimal choice of imprisonment sanctions, taking the probability of sanctions as given. The conclusions are straightforward. First, it is best to employ sanctions that are sufficient to deter whenever deterrence is achievable given the probability of sanctions. Whether deterrence is achievable depends in part on an incapacitative enhancement to deterrence: when a person is imprisoned, he forgoes the gains he would obtain from crimes he would otherwise commit - which serves to deter, along with the disutility of imprisonment.

Second, if deterrence is not achievable given the probability of sanctions, it may still be desirable to employ sanctions in order to incapacitate. The condition under which incapacitation is advantageous is that the cost of imprisonment is less than the incapacitation benefit. This benefit is the net social harm from the crimes the person would commit if he were not in prison (which is endogenous to the model, as the crimes he would commit if he were not in prison will depend on deterrence).

I then find the optimal probability of sanctions. Increasing the probability augments deterrence when that is possible, and it also results in greater incapacitation benefits when such benefits exist (because more individuals who are worth incapacitating are caught). However, raising the probability involves additional costs of enforcement. At the optimal probability of sanctions, potentially deterrable individuals might or might not be deterred, and in the latter case it might be desirable to incapacitate them. ${ }^{2}$

The possible optimality of not deterring potentially deterrable individuals and instead of apprehending them in order to incapacitate them bears comment. The explanation for this

\footnotetext{
${ }^{2}$ See in particular Proposition 3(b)(i).
} 
outcome is that, on one hand, it can be expensive, and thus uneconomic, for society to invest enough in enforcement resources to achieve deterrence. (To deter many types of crime, a very high probability of sanctions might be needed.) Yet, on the other hand, it can still be worthwhile for society to invest a lower amount to capture and imprison individuals for the purpose of incapacitation - even though these individuals could have been deterred if the probability of sanctions had been higher. In other words, one may view the use of prison to incapacitate as a rational economic choice reflecting a social desire to save the enforcement resources that would be needed to deter.

In Section 3, I comment on the conclusions from the model.

Before proceeding, let me note that the economic literature on the theory of crime and imprisonment has focused on deterrence, usually to the exclusion of incapacitation. ${ }^{3}$ There are, however, three articles addressing incapacitation theoretically to which this article relates. Miceli (2010) examines a model of incapacitation and deterrence and solves for the optimal length of imprisonment, but takes the probability of imprisonment as exogenous; Kessler and Levitt (1999) consider a model of incapacitation and deterrence and describe the effect of an increase in imprisonment sanctions, but do not solve for the optimal length of imprisonment or

\footnotetext{
${ }^{3}$ The earliest economically-oriented writing on crime is almost entirely devoted to deterrence. Specifically, Beccaria (1764) and Bentham (1789) elaborately analyse deterrence but mention incapacitation only in passing (Beccaria on p. 36, Bentham on pp. 196-97). Modern economic literature on crime begins with Becker (1968), who restricts his attention to deterrence. Surveys of the economic theory of crime are in the same vein. For example, Garoupa (1997) does not address incapacitation, and Polinsky and Shavell (2000) refer to it only on pp. 68-70. The empirical economic literature on crime has paid somewhat more, but still limited, attention to incapacitation. See, for example, the reviews of empirical work in Miles and Levitt (2007) on pp. 471-74 and 487-89 and in Abrams (2013) on pp. 936-39.
} 
the optimal probability of sanctions; ${ }^{4}$ and Shavell (1987a) determines the optimal length and probability of imprisonment, but in a model of pure incapacitation. ${ }^{5}$

This article appears to be the first to analyze both the optimal length and the optimal probability of imprisonment in a model involving deterrence and incapacitation. Its main contribution is the point that society may find incapacitation an advantageous policy not merely for incorrigible individuals, but also for potentially deterrable individuals - essentially because the policy of incapacitation allows society to conserve on enforcement resources and still to achieve useful prevention of crime.

\section{The Model}

Time in the model is divided into periods. In each period, a cohort of identical individuals of size 1 enters the population and lives for two periods. Thus, the population in each period consists of a young cohort that just entered and an old cohort that entered the previous period. ${ }^{6}$ The total population is 2 each period.

At the beginning of every period, each person chooses whether to commit a harmful act, called a crime, unless he is in prison at the beginning of the period (a possibility to be described). If a person commits a crime, he obtains a benefit $b>0$ and causes a harm $h>0$, where $b<h$.

\footnotetext{
${ }^{4}$ Their purpose is instead to motivate their empirical analysis, in which they are able to separate the influence of deterrence from that of incapacitation.

${ }^{5}$ Ehrlich $(1973,1981)$ is also of note, as he studies incapacitation along with deterrence. Ehrlich emphasizes the idea that the social benefit of incapacitation may be offset by the replacement of imprisoned criminals by new criminals. For example, if car thieves are imprisoned, new car thieves may emerge in order to satisfy the demand for stolen cars. However, Ehrlich does not analyze an explicit multiperiod model of crime (nor does he need to do so to in order to advance his argument concerning replacement effects).

${ }^{6}$ I confine attention to a steady state, so that there will always be a past period in which a cohort entered.
} 
This latter assumption is made in order that the acts called crimes are socially undesirable (the social objective is defined below).

A person who commits a crime in a period might be caught and suffer a sanction of imprisonment, which will begin in the period of the crime. If an individual is not caught for committing a crime in the first period of his life, he will not be caught in the second period for his crime in the earlier period. Also, individuals who decide not to commit a crime in a period are never mistakenly caught and sanctioned.

The sanction of imprisonment is a discrete number of periods. The sanction for a young person, denoted $s_{1}$, can be 0,1 , or 2 periods; if the sanction is 1 period, it is suffered over the first period of the person's life, and if the sanction is 2 periods, it is suffered over both periods of his life. The sanction for an old person, denoted $s_{2}$, can be 0 or 1 .

When a person is in prison, he suffers disutility $d>0$ per period and the state incurs a cost $k>0$ per period associated with the operation of prisons. If $b \leq d$, I will say that the person is potentially deterrable because it will be seen to be possible to deter him from committing the crime in both periods if the probability of sanctions is sufficiently high. This assumption will be my focus because my chief object is to investigate deterrence together with incapacitation. However, I will also consider the case in which $b>2 d$, which I will refer to as that in which a person is undeterrable because it will be seen to be impossible to deter him from committing the crime in either period regardless of the probability of sanctions. ${ }^{7}$

\footnotetext{
${ }^{7}$ It will be evident that if $2 d \geq b>d$, then a person is neither undeterrable nor potentially deterrable: he can be deterred from committing the crime in period 1 if $p$ is high enough and $s_{1}=2$ (so is not undeterrable); but he cannot be deterred from committing the crime in period 2 (so is not potentially deterrable). For simplicity, I do not analyze this case.
} 
The probability of being caught and sanctioned for committing a crime is $p$ and is the same for young and for old individuals. The cost to the state per period of maintaining $p$ is $c(p)$, where $c(0)=0$ and $c^{\prime}(p)>0$.

The social objective is to minimize total social costs: the net social costs due to crime, that is, $h-b$ multiplied by the number of crimes committed; plus the costs of imprisonment, that is, $d+k$ multiplied by the number of periods of imprisonment experienced; plus the costs $c(p)$ of law enforcement.

More precisely, the social objective is to minimize social costs on a per period basis in a steady state. It should be noted that minimization of social costs per period in a steady state is equivalent to minimization of social costs per cohort of individuals over its lifetime: in each period, there is a cohort of young individuals and a different cohort of old individuals; and each cohort experiences one period when it is young and one period when it is old.

The policy instruments employed by the state to minimize social costs are the sanctions $s_{1}$ and $s_{2}$ and the probability $p$ of sanctions.

Let me now examine the behavior of individuals as a function of the $s_{i}$ and $p$.

Consider first an old person, presuming that he is not already in prison in the beginning of the second period of his life. (If he is in prison then, there is no behavior to consider.) If he faces no sanction, $s_{2}=0$, then he will commit a crime when

$$
b>0,
$$

so that he will definitely do so. If, however, $s_{2}=1$, an old person will commit a crime only when (2) $\quad b>p d$ or $p<b / d$, 
since $d$ is the disutility of the one-period sanction. ${ }^{8}$ Note that $b / d \leq 1$ for potentially deterrable individuals, so that deterrence of them is possible if $p$ is sufficiently high. For undeterrables (2) always holds.

Let $v$ stand for the value of a person's payoff in the period when he is old, provided that he is not already in prison at the beginning of that period. Thus $v$ is determined as described in the preceding paragraph. Hence, if the person is deterred, then $v=0$; if he is not deterred and $s_{2}$ $=0$, then $v=b$; and if he is not deterred and $s_{2}=1$, then $v=b-p d$.

Consider next a young person and suppose that $s_{l}=0$. If he commits a crime, his payoff (over both periods) will be $b+v$, whereas if he does not commit a crime, his payoff will be $v$. Hence, he will commit a crime if $b+v>v$, or if (1) holds.

Now consider a young person and suppose that $s_{1}=1$. If he commits a crime, his payoff will be $b-p d+v$, and if he does not commit a crime, his payoff will be $v$. Thus, he will commit a crime if (2) holds.

Finally, consider a young person and suppose that $s_{1}=2$, life imprisonment. In this case, if he commits a crime, his payoff will be

$$
b-p 2 d+(1-p) v
$$

The reason is that if he is caught and put in prison for both periods of his life, he will not obtain $v$, whereas if he is not caught, which occurs with probability $1-p$, he will obtain $v$. And, again, if a young person does not commit a crime, he will obtain $v$. Hence, the young person will commit a crime if $b-p 2 d+(1-p) v>v$, or if (4) $b>p(2 d+v)$.

\footnotetext{
${ }^{8}$ I assume for concreteness that an individual will refrain from committing a crime if the benefit just equals the expected sanction.
} 
In other words, the effective sanction when $s_{l}$ is 2 is the disutility $2 d$ from two periods of imprisonment plus the loss $v$ of what he would have been enjoyed in period 2 had he been free at the beginning of that period. Notably, if $s_{2}$ is 0 , we know that an old person would commit a crime and obtain $b$ if free at the beginning of the period 2. Hence, in this case, $v$ is $b$, so that (4) would become $b>p(2 d+b)$; the effective sanction would include the benefit $b$ from crime that would be forgone due to incapacitation, so that deterrence would involve what was referred to in the introduction as an incapacitative enhancement. Another possibility is that $s_{2}$ is 1 and $b \leq p d$, so that the old person would be deterred from committing a crime. In this case, $v$ is 0 , meaning that (4) would reduce to $b>p 2 d$, and there would be no incapacitative enhancement to deterrence.

Incapacitation can come about in this model only when a person is in prison at the beginning of a period - for that is when he would decide to commit a crime if he were free. Hence, incapacitation can come about only in period 2 of a person's life, and only as a result of the imposition of a two period sanction when he was young. The social benefit from incapacitation in period 2 of a person's life is as follows. If $s_{2}$ is 0 , so that he would have committed the crime and not been sanctioned when old, he would have generated social losses of $h-b$; thus the benefit from incapacitation in that period would be $h-b$. If $s_{2}$ is 1 and he would have been deterred from committing the crime, then he would have generated no social losses, so the incapacitation benefit would be zero. And if $s_{2}$ is 1 and he would not have been deterred from committing the crime, he would have generated social losses of $h-b+p(d+k)$, so that would have been the incapacitation benefit. This shows how the incapacitation benefit depends on possible sanctions and on possible deterrence in period 2 of a person's life. I will refer below to 


$$
2(d+k)<h-b
$$

as the incapacitation condition. On the left is the social cost of imprisonment for two periods; and on the right is the social benefit from incapacitation in period 2 when, in that period, the individual would have committed a crime and the sanction for doing so would have been zero.

Having described the determination of the behavior of individuals given the sanctions $s_{i}$ and $p$, and how incapacitation arises, I can now ascertain the optimal $s_{i}$ and $p$. I will denote the optimal sanctions as a function of $p$ as $s_{1}^{*}(p)$ and $s_{2}^{*}(p)$ and the optimal $p$ as $p^{*}$. We first have

Proposition 1. Assume that individuals are potentially deterrable. Then optimal sanctions $s_{1}{ }^{*}(p)$ for the young and $s_{2}{ }^{*}(p)$ for the old, conditional on the probability $p$ of sanctions, and the outcomes under these optimal sanctions, are as follows.

(a) If $p$ is in region $\mathrm{C}=[\mathrm{b} / \mathrm{d}, 1]$, then $s_{1} *(p)=1$ or 2 and $s_{2} *(p)=1$. Complete deterrence is achieved, no one is imprisoned, and social costs are $c(p)$.

(b) If $p$ is in region $\mathrm{B}=[b /(2 d+b), b / d)$, then $s_{1} *(p)=2$ and $s_{2} *(p)=0$. Deterrence of the young is achieved, but deterrence of the old is not achieved. No one is imprisoned, and social costs are $c(p)+(h-b)$.

(c) If $p$ is in region $\mathrm{A}=[0, b /(2 d+b))$, deterrence of individuals is not possible, and there are two cases. First, if the incapacitation condition, $2(d+k)<h-b$, does not hold, then $s_{1}^{*}(p)=$ 0 and $s_{2} *(p)=0$, no one is imprisoned, and social costs are $c(p)+2(h-b)$. Second, if the incapacitation condition holds, then $s_{1} *(p)=2$ and $s_{2} *(p)=0$, some individuals are imprisoned, and social costs are $c(p)+2(h-b)-p[(h-b)-2(d+k)]$.

Proof. See the Appendix. 
Notes. (a) In region C, $p$ is sufficiently high that it is possible to deter everyone. Hence, it must be optimal to choose sanctions to accomplish complete deterrence, for that will mean that social costs, apart from $c(p)$, will be zero.

(b) In region $\mathrm{B}, p$ is insufficient to deter the old but is sufficient to deter the young. The reason that the young can be deterred but the old cannot is that for the young, a life sentence is 2 periods, whereas for the old, it is only 1 period. Accordingly, it is optimal to choose sanctions to deter the young but not to impose sanctions on the old. Note that there can be no incapacitation in region B because the only way incapacitation can arise is through use of a sanction of 2 that fails to deter. But if a sanction of 2 is used, deterrence will be successful.

(c) In region A, $p$ is insufficient to deter anyone. Hence, the only reason that it could be beneficial to impose sanctions is to accomplish incapacitation. Imprisoning an old person for a crime committed in period 2 of his life cannot accomplish incapacitation, for there is no future time during which he could commit a crime. Hence, it is only the young for whom a sanction could accomplish incapacitation, and that would be true only if the sanction is 2 . The total social cost of a sanction of 2 is $2(d+k)$, and the social benefit is $h-b$, since we know that in period 2 an old person would commit a crime and would not be sanctioned. Hence, incapacitation will be worthwhile if $2(d+k)<h-b$, which is the incapacitation condition. Note that this condition is independent of $p$.

(d) To illustrate the proposition, suppose that $b=10$ and $d=20$. Then $\mathrm{A}=[0, .2), \mathrm{B}=$ $[.2, .5)$, and $\mathrm{C}=[.5,1]$. Hence, for $p$ at least .5 , deterrence of all individuals is best, through the use of sanctions for the young and the old. In this case, for any $p$ in C, minimized social costs are $c(p)$. For lower $p$ but at least .2, deterrence of the young only is possible and best, through the use of a sanction of 2 for the young and no sanctions for the old. Thus, for any $p$ in $\mathrm{B}$, social 
costs are $c(p)+h-10$. For $p$ below .2, what is optimal depends on whether the incapacitation condition holds. Suppose that $k=5$ and $h=100$. Then the incapacitation condition holds; incapacitation is worthwhile, since $2(20+5)=50$, the cost of incapacitation, is less than $100-$ $10=90$, its benefit. Hence, it is best to incapacitate by using a sanction of 2 for the young but no sanctions for the old. Social costs are thus $c(p)+180-p(90-50)$, where the last term is the net benefit of incapacitation. On the other hand, if $k=5$ and $h=40$, the incapacitation condition does not hold, since the benefit of incapacitation would be only $40-10=30$, so that no use of sanctions would be best in A. Social costs are therefor $c(p)+60$.

(e) The effects of changes in the parameters is clear from the proposition. As $b$ increases, deterrence becomes more difficult; $b /(2 d+b)$ increases, meaning that region $\mathrm{B}$ and $\mathrm{C}$, over which partial or complete deterrence are achieved, shrinks. Also, an increase in $b$ makes satisfaction of the incapacitation condition less likely and thus that imprisonment will be desirable to employ in region A. In contrast, as $d$ increases, deterrence becomes easier; $b /(2 d+$ b) decreases, implying that the region $\mathrm{B}$ and $\mathrm{C}$ expands. Also, satisfaction of the incapacitation condition and the use of imprisonment in region A becomes less likely. As $h$ increases, there is no effect on deterrence or on the regions A, B, and C. However, satisfaction of the incapacitation condition becomes more likely. Finally, as $k$ increases, there is no effect on deterrence or on the regions $\mathrm{A}, \mathrm{B}$, and $\mathrm{C}$, but satisfaction of the incapacitation condition becomes less likely.

With regard to undeterrable individuals, the conclusion is as follows.

Proposition 2. Assume that individuals are undeterrable. Then optimal sanctions do not depend on $p$, and there are two cases. First, if the incapacitation condition, $2(d+k)<h-b$, does not hold, then $s_{1}{ }^{*}(p)=0$ and $s_{2}{ }^{*}(p)=0$, no one is imprisoned, and social costs are $c(p)+2(h-$ 
b). Second, if the incapacitation condition holds, then $s_{1} *(p)=2$ and $s_{2} *(p)=0$, some individuals are imprisoned, and social costs are $c(p)+2(h-b)-p[(h-b)-2(d+k)]$.

Proof. See the Appendix.

Note. Because individuals are not deterrable, it is clear that $p$ cannot influence the optimal sanctions and that only the incapacitation condition can be relevant to them.

Now that I have examined the optimal sanctions $s_{i}$ as a function of $p$, I can determine $p^{*}$, the optimal $p$. For potentially deterrables, I will need to refer to $p_{A}{ }^{*}$, which is defined to be the optimal $p$ (or an optimal $p$ if not unique) within region $\mathrm{A}=[0, b /(2 d+b))$ when the incapacitation condition holds, provided that $p_{A}{ }^{*}$ exists. ${ }^{9}$ We have

Proposition 3. Assume that individuals are potentially deterrable. Then the optimal probability $p^{*}$ and the optimal outcomes under the optimal sanctions are as follows. ${ }^{10}$

(a) If the incapacitation condition does not hold, then $p^{*}$ equals either $0, b /(2 d+b)$, or $b / d$. In particular, let $\min =\min (2(h-b), c(b /(2 d+b))+(h-b), c(b / d))$. Then (i) $p^{*}=0$ if $\min =2(h-b)$. Social costs are $2(h-b)$, no one is deterred, and no one is imprisoned.

(ii) $p^{*}=b /(2 d+b)$ if $\min =c(b /(2 d+b))+(h-b)$. Social costs are $c(b /(2 d+b))+(h-b), s_{1}{ }^{*}$ $=2$ and $s_{2} *=0$, only the young are deterred, and no one is imprisoned.

(iii) $p^{*}=b / d$ if $\min =c(b / d)$. Social costs are $c(b / d), s_{1}^{*}=1$ or 2 and $s_{2} *=1$, all are deterred, and no one is imprisoned.

(b) If the incapacitation condition holds and $p_{A}{ }^{*}$ exists, then $p_{A} *$ is determined by $c^{\prime}\left(p_{A}{ }^{*}\right)$ $=[(h-b)-2(d+k)]$ if $p_{A}{ }^{*}$ is positive. Further, $p^{*}$ equals either $p_{A}{ }^{*}, b /(2 d+b)$, or $b / d$. In

\footnotetext{
${ }^{9}$ Because region $\mathrm{A}$ is open at the right, it will be seen that $p_{A}{ }^{*}$ may not exist.

${ }^{10}$ For expositional convenience, I will not discuss the possibility here and below that $p^{*}$ is not unique.
} 
particular, let $\min =\min \left(c\left(p_{A}^{*}\right)+2(h-b)-p_{A} *[(h-b)-2(d+k)], c(b /(2 d+b))+(h-b)\right.$, $c(b / d))$. Then

(i) $p^{*}=p_{A} *$ if $\min =c\left(p_{A}^{*}\right)+2(h-b)-p_{A} *[(h-b)-2(d+k)]$. Social costs are $c\left(p_{A}^{*}\right)+2(h-$ b) $-p_{A} *[(h-b)-2(d+k)], s_{1}^{*}=2$ and $s_{2} *=0$, no one is deterred, and young individuals are imprisoned for two periods.

(ii) $p^{*}=b /(2 d+b)$ if $\min =c(b /(2 d+b))+(h-b)$. Social costs are $c(b /(2 d+b))+(h-b), s_{1}^{*}$ $=2$ and $s_{2}{ }^{*}=0$, only young individuals are deterred, and no one is imprisoned.

(iii) $p^{*}=b / d$ if $\min =c(b / d)$. Social costs are $c(b / d), s_{1}^{*}=1$ or 2 and $s_{2} *=1$, all are deterred, and no one is imprisoned.

(c) If the incapacitation condition holds and $p_{A} *$ does not exist, then $p^{*}$ equals either $b /(2 d$ $+b)$, or $b / d$. In particular, let $\min =\min (c(b /(2 d+b))+(h-b), c(b / d))$. Then

(i) $p^{*}=b /(2 d+b)$ if $\min =c(b /(2 d+b))+(h-b)$. Social costs are $c(b /(2 d+b))+(h-b), s_{1}^{*}=$ 2 and $s_{2} *=0$, only young individuals are deterred, and no one is imprisoned.

(ii) $p^{*}=b / d$ if $\min =c(b / d)$. Social costs are $c(b / d), s_{1}^{*}=1$ or 2 and $s_{2}{ }^{*}=1$, all are deterred, and no one is imprisoned.

Proof. See the Appendix.

Notes. (a) When the incapacitation condition does not hold, we know from Proposition 1 that incapacitation cannot be optimal, so that the optimal probability is determined entirely by considerations of deterrence. Specifically, there are only two positive probabilities that need to be examined: $b / d$, the minimum probability that will deter all individuals, and $b /(2 d+b)$, the minimum probability that will deter the young but not the old. The optimal probability will be positive and one of these two if the cost of raising $p$ to either level is less than the resulting reduction in social harm accomplished by deterrence. 
(b) When the incapacitation condition holds, we know that if $p$ is in region A, where no one is deterred, incapacitation will be valuable, and social costs will be $c(p)+2(h-b)-p[(h-b)$ $-2(d+k)]$. Note that the last term is the incapacitation benefit, $[(h-b)-2(d+k)]$, the net harm avoided due to incapacitation minus the cost of imprisonment. Presuming that the optimal $p$ conditional on being in this interval, $p_{A}{ }^{*}$, exists and is positive, it will reflect the tradeoff between the cost of raising $p$ and the benefit of accomplishing more incapacitation; thus the firstorder condition determining $p_{A}{ }^{*}$ is that the marginal cost of raising $p, c^{\prime}\left(p_{A}^{*}\right)$, equals the marginal benefit, $[(h-b)-2(d+k)]$. In that case, it is possible that $p^{*}$ is $p_{A}{ }^{*}$ as well as one of the other two higher positive probabilities. Note that if $p^{*}$ is $p_{A}{ }^{*}$ (case (i) of part (b)), then it is optimal to incapacitate individuals even though they are potentially deterrable (as discussed in the introduction.)

(c) When the incapacitation holds, it may be that there is no optimal $p_{A}{ }^{*}$ within region $\mathrm{A}$, notably, because raising $p$ may always lower social costs within A, which is open at the right. In that case, it turns out that deterring at least young individuals is superior to use of any $p$ in region A.

(d) To illustrate Proposition 3(a), consider the example from Proposition 1, with $b=10, d$ $=20, k=5$, and $h=40$, where region $\mathrm{A}=[0, .2)$, region $\mathrm{B}=[.2, .5)$, and region $\mathrm{C}=[.5,1]$. The incapacitation condition does not hold in this example, so that incapacitation is not desirable for $p$ in region A. Thus, the claim of Proposition 3(a) is that $p^{*}$ could be $0, .2$, or .5 . To verify this, note that at $p=0$, social costs are 60 since all individuals commit crimes; at $p=.2$, costs are $c(.2)$ +30 since only the old commit crimes; and at $p=.5$, costs are $c(.5)$ since no one commits crimes. Hence, if $c(.2)=20$ and $c(.5)=40$, then $p^{*}=.5$, for social costs at $p=0$ are 60 , costs at 
$p=.2$ are 50 , and costs at $p=.5$ are $40 .{ }^{11}$ If the costs of raising $p$ are greater, then $p=.2$ could be optimal. Suppose that $c(.2)=20$ but $c(.5)=70$. Then at $p=0$, social costs are 60 , at $p=.2$ costs are 50, and at $p=.5$ costs are 70 . Accordingly, $p^{*}=.2$. Likewise, suppose that $c(.2)=35$ and $c(.5)=70$. Then at $p=0$, social costs are 60 , at $p=.2$ costs are 65 , and at $p=.5$ costs are 70 . Consequently, $p^{*}=0$.

To illustrate Proposition 3(b), consider the example just mentioned but with $h=100$, so that the incapacitation condition holds. Assume that $c(p)$ is such that $p_{A}{ }^{*}=.1$ and that $c(.1)=1$, $c(.2)=88$, and $c(.5)=179 .{ }^{12}$ Then social costs at $p_{A}{ }^{*}$ are $c(.1)+180-.1(40)=177$, costs at $p=$ .2 are $c(.2)+90=178$, and costs at $p=.5$ are $c(.5)=179$. Hence, $p_{A}^{*}=.1$ is best, involving incapacitation and no deterrence, because the cost of raising $p$ becomes much higher above .1 , so that deterrence is not worthwhile achieving. Note as well in this example that incapacitation is best even though achieving deterrence (either of just young individuals or of all individuals) would be better than not controlling crime at all (for with $p=0$, social costs would be 180). That is, if imprisonment did not have its incapacitative feature, it would be socially desirable to deter.

If in the preceding example, $c(.2)=80$, then social costs at $p=.2$ are 170 , so that $p^{*}=.2$; and if $c(.5)=160$, then social costs at $p=.5$ are 160 , so that $p^{*}=.5$.

To illustrate Proposition 3(c), continue to assume that $h=100$, but suppose that $c(p)=$ $10 p$ in $[0, .2]$ and that above that interval $c(p)$ is such that $c(.5)=100$. Then social costs $c(p)+$

\footnotetext{
${ }^{11}$ I have chosen $c(p)$ such that $c(0)$ is $0, c(.2)$ is positive, and $c(.5)$ is greater than $c(.2)$. Such a function $c(p)$ can obviously be found that obeys the assumptions about $c(p)$, that it is increasing and differentiable.

${ }^{12}$ To show that there exists such a $c(p)$, suppose that in $[0, .1], c(p)=10 p$; and in $[.1, .2], c(p)=1+870(p-.1)$. Above .2 , choose any $c(p)$ that is increasing, differentiable, and equals 179 at .5. Hence, $c(p)$ is increasing, $c(0)=0$, $c(.1)=1$, and $c(.2)=88$. Social costs within region $\mathrm{A}=[0, .2)$ are $c(p)+180-40 p$ when $s_{1}=2$ and $s_{2}=0$.

Therefore, in $[0, .1]$, social costs are $180-30 p$ and thus are minimized in that interval at .1. Further, in $[.1, .2]$, social costs are $1+870(p-.1)+180-40 p=94+830 p$ and are minimized at .1 . Hence, social costs over $[0, .2)$ are minimized at .1 , so that $p_{\mathrm{A}}{ }^{*}=.1$ as claimed for $c(p)$. However, $c(p)$ is not differentiable at .1: its derivative from the left is 10 and its derivative to the right is 870 . It is clear that this $c(p)$ could be slightly modified to make it differentiable at 1 without altering the points that the example illustrates.
} 
$180-p(40)=180-30 p$ are strictly decreasing in $[0, .2)$, so that $p_{A} *$ does not exist - it is always better to raise $p$ in region A where incapacitation is socially useful—and social costs tend toward the limit $c(.2)+180-.2(40)=174$ as $p$ approaches .2 from the left. At $p=.2$, however, where the young are deterred, social costs fall to $c(.2)+90=92$, and at $p=.5$, social costs are $c(.5)=$ 100. Hence, $p^{*}=.2$. If in this example, $c(.5)$ were 80 , then social costs would be 80 at .5 , so that $p^{*}$ would be .5 .

(e) With regard to the effect of changes in the parameters on $p^{*}$ and optimal outcomes, consider first $h .^{13}$ If $h$ is sufficiently close to its lower bound $b$, then $p^{*}$ is $0 .^{14}$ The reason is that in the neighborhood of $b$, the social harm from crime is negligible. If $h$ is sufficiently high, in contrast, $p^{*}$ must equal $b / d .^{15}$ The rationale is that as the social harm from crime grows, it must become worthwhile to achieve complete deterrence.

If $b$ is sufficiently close to $0, p^{*}$ will equal $b / d$ and complete deterrence will be optimal. ${ }^{16}$ The reason is that the probability of sanctions needed to achieve complete deterrence, and thus the $\operatorname{cost} c(b / d)$ of doing so, will approach 0 . There are two possible upper bounds of $b$, namely, $d$ and $h$, for I assumed that $b$ does not exceed either. If $b$ is sufficiently close to its upper bound, $h$ (which applies if $h \leq d$ ), $p^{*}$ must be $0 .{ }^{17}$ The reason is that as $b$ approaches $h$, the social harm

\footnotetext{
${ }^{13}$ I restrict my consideration to extreme values of the parameters, for a complete characterization of the changes in the solution as the parameters vary would be tedious.

${ }^{14}$ The incapacitation condition $2(d+k)<h-b$ must fail if $h$ is sufficiently close to $b$. Thus, Proposition 3(a) applies, and $p^{*}$ is determined by $\min (2(h-b), c(b /(2 d+b))+(h-b), c(b / d))$. As $h$ approaches $b$, the latter term tends to $\min \left(0, c(b /(2 d+b), c(b / d))\right.$, which is 0 . Hence, for $h$ sufficiently close to $b, p^{*}$ must be 0 .

${ }^{15}$ It is evident from Proposition 3 that since $h-b$ grows without bound, the minimum of the amounts determining $p^{*}$ must be achieved at $b / d$ for $h$ sufficiently high.

${ }^{16}$ If the incapacitation condition does not hold as $b$ approaches 0 , then under Proposition 3(a), $p^{*}$ is determined by $\min (2(h-b), c(b /(2 d+b))+(h-b), c(b / d))$. The latter term tends to $\min (2 h, h, 0)=0$ as $b$ approaches 0 . Hence, for $b$ sufficiently close to 0 , we must have $p^{*}=b / d$ and obtain complete deterrence. If the incapacitation condition does hold, Propositions 3(b) and 3(c) and similar logic lead to the same conclusion.

${ }^{17}$ This claim follows by essentially the argument given in note 14 .
} 
caused by crime approaches 0 . However, as $b$ tends toward its other upper bound, $d$ (which applies if $d \leq h)$, no conclusions can be drawn about $p^{*}{ }^{18}$

As $d$ approaches its lower bound $b$, again no conclusions can be drawn about $p^{*} \cdot{ }^{19}$ On the other hand, for all $d$ sufficiently large, $p^{*}$ must equal $b / d .^{20}$ The rationale is that as the disutility from punishment grows, the probability needed to achieve complete deterrence tends toward 0 , so it must become worthwhile to achieve complete deterrence.

As $k$ approaches its lower bound, zero, no conclusions can be drawn about $p^{*}{ }^{21}$ If $k$ is sufficiently high, the incapacitation condition will not hold, so that solution cannot involve incapacitation, but no conclusions can be drawn about $p^{*} .^{22}$

With regard to undeterrable individuals, we have

Proposition 4. Assume that individuals are undeterrable. Then the optimal probability $p^{*}$ and the optimal outcomes under the optimal sanctions are as follows.

(a) If the incapacitation condition does not hold, then $p^{*}$ equals 0 and no individuals are sanctioned.

\footnotetext{
${ }^{18}$ The incapacitation condition $2(d+k)<h-b$ may or may not hold as $b$ approaches $d$. Suppose that the condition does not hold, so that Proposition 3(a) applies. Then $p^{*}$ is determined by $\min (2(h-b), c(b /(2 d+b))+(h-b)$, $c(b / d))$, which tends toward $\min (2(h-d), c(1 / 3)+(h-d), c(1))$. The latter term could be minimized at any of its three possible values, establishing that no conclusion can be drawn about $p^{*}$.

${ }^{19}$ This claim follows by essentially the argument given in the previous note.

${ }^{20}$ Since $b / d$ tends toward 0 as $d$ grows, it is evident from Proposition 3 that the minimum of the quantities determining $p^{*}$ must be achieved at $b / d$ for $d$ sufficiently high.

${ }^{21}$ The incapacitation condition $2(d+k)<h-b$ may or may not hold as $k$ approaches 0 . Suppose that the condition does not hold, so that Proposition 3(a) applies. Then $p^{*}$ is determined by $\min (2(h-b), c(b /(2 d+b))+(h-b)$, $c(b / d)$ ). This term could be minimized at any of its three possible values, establishing that no conclusions can be drawn about $p^{*}$.

${ }^{22}$ It is clear that the incapacitation condition must hold for $k$ sufficiently high, and then from Propostion 3(a) that $p^{*}$ could equal any of its three possible values.
} 
(b) If the incapacitation condition holds, then $p^{*}$ could be anywhere in the interval $[0,1]$. If $p^{*}$ is in $(0,1)$, it is determined by $c^{\prime}\left(p^{*}\right)=[(h-b)-2(d+k)]$. If $p^{*}$ is positive, then $s_{l}\left(p^{*}\right)=$ $2, s_{2}\left(p^{*}\right)=0$, and some individuals are sanctioned.

Proof. See the Appendix.

Notes. It clearly can be optimal to employ a positive probability only if the incapacitation condition holds, in which case it is optimal to sanction the young in order to incapacitate them. In that case, if the optimal probability is interior, it will be determined by the first-order condition that the marginal cost of raising $p$ equals the marginal incapacitation benefit, $[(h-b)-2(d+k)]$

\section{Comments}

Several possible extensions of the model are worth noting. One is to allow for variations in the benefits that individuals obtain from crime, the harm caused by it, and the disutility of sanctions. Under the assumption that the state can observe these variables, the conclusions would be similar to those found above. In particular, if a person of a given type could be deterred given the probability of sanctions, the sanction would be chosen to accomplish that objective; otherwise, the person would be imprisoned if and only if the benefits from incapacitation would outweigh the costs. Furthermore, the optimal probability of sanctions would reflect the same tradeoffs as were discussed, involving the cost of raising the probability, the advantage of achieving greater deterrence and incapacitation as a consequence, and also the fact that it may be desirable to employ a low probability to save enforcement resources because incapacitation can still usefully prevent crime.

A second extension is to consider the model just sketched with different types of individuals, but to assume that the state's information about an individual's benefits from crime 
and the disutility he would experience from sanctions is imperfect. Then the use of sanctions to deter would sometimes fail to achieve that result and lead to the actual imprisonment of individuals. $^{23}$ As a consequence, imprisonment would often occur even though it would not be justified by incapacitation.

A third extension is to permit a longer life than two periods and also benefits and harm from crime that decline with age. Among other things, this would lead to the optimality of limited periods of imprisonment for the purposes of incapacitation and also to the possibility of recidivism. $^{24}$

More generally, it seems that in the future agenda of theoretical work on crime and imprisonment, incapacitation should receive due attention along with deterrence. This view flows from two points that have been stressed here. First, incapacitation is a byproduct of imprisonment, meaning that it is a logical necessity to take incapacitation into account in any multiperiod model of deterrence. And second, it may be socially advantageous to employ imprisonment to incapacitate rather than to deter, in order to save the enforcement resources that would be needed to accomplish better deterrence.

\footnotetext{
${ }^{23}$ For example, if the state underestimated the benefit $b$ from crime or overestimated the disutility $d$ of imprisonment, the state might fail to deter. On the information of the state and the optimal use of imprisonment for deterrence, see Shavell (1987b).

${ }^{24}$ Incapacitation could become undesirable with age because, when the benefit from crime declines sufficiently, the motive to engage in it falls, and when the harm from crime declines sufficiently, the potential social savings from incapacitation fall. Recidivism is possible because the state may have imperfect information about the benefits from crime and the disutility of prison.
} 


\section{References}

Abrams, David. 2013. “The Imprisoner's Dilemma: A Cost-Benefit Approach to Incarceration." Iowa Law Rev. 98: 905-69.

Beccaria, Cesare. 1764. An Essay on Crimes and Punishments. Adolph Caso, editor. Boston:International Pocket Library, 1962 (originally published 1764).

Bentham, Jeremy. 1789. An Introduction to the Principles of Morals and Legislation. Oxford: Clarendon Press, reprint of "A New Edition," 1823 (originally published 1789).

Ehrlich, Isaac. 1973. "Participation in Illegitimate Activities: A Theoretical and Empirical Investigation." J. Polit. Econ. 81: 521-65.

Ehrlich, Isaac. 1981. "On the Usefulness of Controlling Individuals: An Economic Analysis of Rehabilitation, Incapacitation, and Deterrrence." Amer. Econ. Rev. 71: 307-32.

Garoupa, Nuno. 1997. "The Theory of Optimal Law Enforcement.” J. Econ. Surveys. 11: 26795.

Kessler, Daniel P., and Steven D. Levitt. 1999. "Using Sentence Enhancements to Distinguish between Deterrence and Incapacitation." J. Law and Econ. 17 (1): 343-63.

Miceli, Thomas J. 2010. "A model of criminal sanctions that incorporate both deterrence and incapacitation." Econ. Letters. 107: 205-07.

Miles, Thomas J., and Steven D. Levitt. 2007. "Empirical Study of Criminal Punishment." Ch. 7 in Handbook of Law and Economics, A. Mitchell Polinsky and Steven Shavell, editors. Amsterdam: North Holland. 1: 455-95.

Polinsky, A. Mitchell, and Steven Shavell. 2000. "The Economic Theory of Public Enforcement of Law." J. Econ. Lit. 38: 45-76.

Shavell, Steven. 1987a. “A Model of Optimal Incapacitation.” Amer. Econ. Rev.: Papers and Proc. 77: 107-10.

Shavell, Steven. 1987b. "The Optimal Use of Nonmonetary Sanctions as a Deterrent." Amer. Econ. Rev. 77: 584-92. 


\section{Appendix}

\section{Proof of Proposition 1.}

(a) For any $p$ in region C, consider the policy $s_{1}=1$ and $s_{2}=1$. We know from (2) that both an old person and a young person will commit a crime only if $b>p d$, but this does not hold in C. Hence, there will be complete deterrence under $s_{1}=1$ and $s_{2}=1$, and social costs each period will be $c(p)$. Since social costs cannot be lower than $c(p)$, the sanctioning policy must be optimal. It is easily verified that behavior is the same under $s_{1}=2$ and $s_{2}=1$, so that that sanctioning policy too must be optimal. It is also readily seen that behavior is different under any other sanctioning policy, so such policies must be suboptimal.

(b) For any $p$ in region $\mathrm{B}$, consider the policy $s_{1}=2$ and $s_{2}=0$. Then an old person (who is not in prison) will commit a crime, so he will obtain $b$ for sure. A young person will commit a crime if $b>p(2 d+b)$, as was noted follows from (4). But this inequality does not hold for $p$ in B. Consequently, the young are deterred, and social costs are $c(p)+(h-b)$.

Next consider other sanctioning policies. If $s_{1}=0$ or 1 and $s_{2}=0$, the old will still commit crimes and the young will also do so. In particular, we know from above that if $s_{l}=0$, the young will commit crimes, and that if $s_{1}=1$, they will do so if (2) holds, which it does. Hence, social costs must be higher than $c(p)+(h-b)$.

Last, consider sanctioning policies under which $s_{2}=1$. Then, we know from (2) that the old commit crimes if they are not in prison. There are then two possibilities. One is that no old individuals are in prison in the beginning of period 2. If so, all old individuals commit crimes, implying that social costs are at least $c(p)+(h-b)+p(d+k)$. The other possibility is that some old individuals are in prison at the beginning of period 2. But that could be the case only if 
young persons commit crimes, implying that social costs are again at least $c(p)+(h-b)+p(d+$ $k)$. Since these costs exceed $c(p)+(h-b)$, policies with $s_{2}=1$ cannot be optimal.

(c) For any $p$ in region A, we know from (2) that it is not possible to deter old individuals.

Furthermore, it is also impossible to deter the young. In particular, we know from (4) that if $s_{1}=2$ and $s_{2}=0$, the young will commit crimes if $b>p(2 d+b)$, or $p<b /(2 d+b)$, which holds in A. If $s_{1}=2$ and $s_{2}=1$, (4) implies that the young will commit crimes if $b>p(2 d+b-$ $p d)$, or equivalently, if $b-2 p d>p(b-p d)$, which holds in region $\mathrm{A}^{25}$ In addition, we know from above that if $s_{1}$ is 0 , the young will commit crimes when (1) holds, and that if $s_{l}$ is 1 , they will commit crimes if (2) holds. Hence, the young will definitely commit crimes.

To compute social welfare under the different possible sanctioning regimes is now simple because we know that no one will be deterred.

If $s_{1}=2$ and $s_{2}=0$, social costs will be $c(p)+(h-b)+p 2(d+k)+(1-p)(h-b)$ since the old will commit crimes only if not caught when young; equivalently, social costs are $c(p)+$ $2(h-b)-p[(h-b)-2(d+k)]$.

If $s_{1}=0$ and $s_{2}=0$, social costs will be $c(p)+2(h-b)$.

Any other sanctioning policy must be inferior to one of the two policies just stated. In particular, if $s_{1}=1$ and $s_{2}=0$, social costs will be $c(p)+2(h-b)+p(d+k)$, so this policy is inferior to $s_{1}=0$ and $s_{2}=0$. If $s_{1}=1$ and $s_{2}=1$, social costs will be $c(p)+2(h-b)+2 p(d+k)$, so this policy is also inferior to $s_{1}=0$ and $s_{2}=0$. If $s_{1}=0$ and $s_{2}=1$, social costs will be $c(p)+$ $2(h-b)+p(d+k)$, which is again inferior to $s_{1}=0$ and $s_{2}=0$. If $s_{1}=2$ and $s_{2}=1$, social costs

\footnotetext{
${ }^{25}$ Since $p<b /(2 d+b)$ in A, we know that $b>2 p d+p b$, or that $b-2 p d>p b$. And since $p b>p(b-p d)$, we have that $b-2 p d>p(b-p d)$.
} 
will be $c(p)+(h-b)+p 2(d+k)+(1-p)[(h-b)+p(d+k)]$, so that this policy is inferior to $s_{1}$ $=2$ and $s_{2}=0$.

It follows that one of the first two policies must be optimal. Specifically, $s_{1}=2$ and $s_{2}=0$ will be superior to $s_{1}=0$ and $s_{2}=0$ when $c(p)+(h-b)+p 2(d+k)+(1-p)(h-b)<c(p)+2(h$ $-b) .{ }^{26}$ Equivalently, $s_{1}=2$ and $s_{2}=0$ will be the superior policy when $2(d+k)<(h-b)$, which is (5).

\section{Proof of Proposition 2.}

This is clear from the last five paragraphs of the proof of Proposition 1(c).

\section{Proof of Proposition 3.}

(a) When (5) does not hold, we know from Proposition 1(c) that if $p$ is in $[0, b /(2 d+b))$, minimized social costs given $p$ are $c(p)+2(h-b)$. Hence, the optimal $p$ within that interval is 0 and social costs are $2(h-b)$. We also know from Proposition $1(\mathrm{~b})$ that if $p$ is in $[b /(2 d+b), \mathrm{b} / \mathrm{d})$, then minimized social costs are $c(p)+(h-b)$. Thus, within this interval, social costs are minimized when $p$ is $b /(2 d+b)$ and thus social costs are $c(b /(2 d+b))+(h-b)$. From Proposition 1(a), we know that when $p$ is in $[b / d, 1]$, minimized social costs are $c(p)$. In this interval, social costs are minimized when $p$ is $b / d$, so that social costs are $c(b / d)$. Consequently, the optimal level of social costs must equal $\min (2(h-b), c(b /(2 d+b))+(h-b), c(b / d))$. From these observations and Proposition 1, Proposition 3(a) follows.

(b) When (5) holds, we know from Proposition 1(c) that if $p$ is in $[0, b /(2 d+b))$, minimized social costs are $c(p)+2(h-b)-p[(h-b)-2(d+k)]$. The derivative of social costs

\footnotetext{
${ }^{26} \mathrm{I}$ am assuming for concreteness that $s_{1}=0$ and $s_{2}=0$ is the policy that will be employed when social costs under the two policies are equal.
} 
with respect to $p$ is thus $c^{\prime}(p)-[(h-b)-2(d+k)]$. Hence, if $p_{A}^{*}>0$ and is in region $\mathrm{A}$, then $c^{\prime}\left(p_{A}^{*}\right)=[(h-b)-2(d+k)]$ holds, as claimed in Proposition 3(b). (It is also obvious that $p_{A}^{*}=$ 0 is possible; that would be so, for example, if $c^{\prime}(p)>[(h-b)-2(d+k)]$ for all $p$ in region A.) The other claims in Proposition 3(b) follow by essentially the logic showing Proposition 3(a).

(c) When (5) holds but $p_{A} *$ does not exist, I wish to show that social costs are lower at $b /(2 d+b)$ than in $\mathrm{A}=[0, b /(2 d+b))$. We know from Proposition $1(\mathrm{c})$ that for $p$ in region $\mathrm{A}$, social costs are $c(p)+2(h-b)-p[(h-b)-2(d+k)]$, which I will denote here by $s(p)$. Let $m$ be the minimum of $s(p)$ on $[0, b /(2 d+b)]$, which must exist because $s(p)$ is a continuous function and the interval is closed. I claim that $m$ is uniquely achieved at $p=b /(2 d+b)$ : otherwise $m$ would be achieved at some point $p_{m}$ in the half open interval $[0, b /(2 d+b))$, implying that $p_{m}$ would minimize $s(p)$ over that interval, which would contradict the assumption that $p_{A} *$ does not exist. Consequently, we know that $s(b /(2 d+b))<s(p)$ for all $p$ in $[0, b /(2 d+b))$. But $s(b /(2 d+$ $b))=c(b /(2 d+b))+2(h-b)-b /(2 d+b)[(h-b)-2(d+k)]>c(b /(2 d+b))+2(h-b)-(h-b)$, since $b /(2 d+b)[(h-b)-2(d+k)]<h-b($ for $b /(2 d+b)<1$ and the term in brackets is less than $h-b)$. But $c(b /(2 d+b))+2(h-b)-(h-b)=c(b /(2 d+b))+(h-b)$, which are social costs if $p$ $=b /(2 d+b)($ see Proposition 1(b)). Hence, we have that for all $p$ in $[0, b /(2 d+b)), s(p)>$ $c(b /(2 d+b))+(h-b)$, meaning that $p=b /(2 d+b)$ is superior to any $p$ in region A. From this conclusion, the rest of Proposition 3(c) follows.

\section{Proof of Proposition 4.}

(a) This is obvious from Proposition 2.

(b) Since the incapacitation condition holds, we know from Proposition 2 that minimized social costs are $c(p)+2(h-b)-p[(h-b)-2(d+k)]$, the derivative of which is $c^{\prime}(p)-[(h-b)-$ 
$2(d+k)]$. Hence, if $p^{*}$ is not a corner solution (which is clearly possible), then it is determined by $c^{\prime}(p)=[(h-b)-2(d+k)]$ and could lie anywhere in $(0,1)$. 